\title{
SOBRE EL CONOCIMIENTO DEL COMPRADOR, ANTES DE LA FIRMA DEL CONTRATO O DEL CIERRE, DE LA FALSEDAD DE LAS DECLARACIONES Y GARANTÍAS
}

\author{
ABOUT THE BUYER'S KNOWLEDGE, BEFORE SIGNING THE \\ CONTRACT OR CLOSING, OF THE FALSITY OF REPRESENTATIONS \\ AND WARRANTIES
}

Joaquín Recart Apfelbeck*

RESUMEN: El artículo analiza el efecto del conocimiento del comprador, antes de la firma de un contrato, o del cierre, acerca de la falsedad de una o más declaraciones y garantías. Se revisa el caso en que las partes guardan silencio sobre el punto. Se argumenta que en el Derecho chileno, el conocimiento efectivo del comprador afecta su derecho a reclamar de la infracción de las declaraciones y garantías.

Palabras clave: declaraciones y garantías, incumplimiento contractual, responsabilidad estricta, conocimiento, excusas.

ABSTRACT: This paper analyses the effect of the buyer's knowledge, before signing or closing, about the falsity of one or more representations and warranties. It focuses on the case in which the parties do not address the issue in the contract. It holds that under Chilean law the actual knowledge by the buyer affects its ability to bring a claim for the breach of the representations and warranties.

Keywords: representations and warranties, breach of contract, strict liability, knowledge, defenses.

\section{INTRODUCCIÓN}

En Chile resulta bastante común el uso de declaraciones y garantías en todo tipo de contratos, particularmente en compraventas de empresas. Las declaraciones y garantías son un mecanismo que distribuye entre los contratantes el riesgo de que una afirmación efectuada por uno de ellos no se ajuste a la realidad. Este riesgo lo soporta la parte que realiza la declaración, y la extensión del primero dependerá de la amplitud de la segunda ${ }^{1}$.

Las declaraciones y garantías permiten superar o disminuir "la dificultad que tiene uno de los contratantes de determinar, por sí mismo, todas las características del objeto del contrato y riesgos asociados al mismo"2. Tanto el otorgamiento de declaraciones y garantías por par-

\footnotetext{
Máster en Derecho, Columbia University, y magister en Derecho, con mención en Derecho Privado, Universidad de Chile. Profesor de Derecho Civil, Universidad de Chile. Dirección postal: Pío Nono No 1, Providencia. Correo electrónico jrecart@derecho.uchile.cl. Agradezco especialmente a Cristián Banfi por sus valiosos comentarios a un borrador de este artículo.

1 STARK (2007) p. 17. Todas las traducciones contenidas en este artículo son mías.

2 Cárdenas y Reveco (2018) p. 150.
} 
te del vendedor, como la realización de un due diligence de la cosa por parte del comprador, tienden a contrarrestar la asimetría de información existente entre aquel -quien generalmente conoce la cosa- y este, quien suele tener menor conocimiento de ella. Este mecanismo permite al declarante revelar información dentro de la relación contractual, y al destinatario adquirir dicha información ${ }^{3}$. Asimismo, el incumplimiento de las declaraciones y garantías da lugar a responsabilidad contractual estricta fundada en la insatisfacción del interés del acreedor en la veracidad de las afirmaciones, sin que el declarante pueda oponer excusa alguna ${ }^{4}$.

En este artículo analizaré el efecto del conocimiento por parte del comprador, como receptor de las declaraciones y garantías, de la falsedad de estas, antes de la firma del contrato de compraventa de la cosa o empresa, o antes del cierre del mismo, si este incluye firma y un cierre posterior, particularmente cuando las partes no han regulado los efectos de dicho conocimiento. Por cierre o closing entiendo la materialización o consumación de una transacción, que suele implicar el traspaso de la propiedad y el pago ${ }^{5}$. El cierre a que aludo no debe confundirse con el cierre de negocios. Este último corresponde a un acuerdo preliminar precontractual, que no genera la obligación de celebrar un contrato definitivo, pero cuyo incumplimiento puede dar lugar a responsabilidad precontractual, o a la multa que hayan establecido las partes ${ }^{6}$.

Específicamente, la pregunta que intentaré responder es si el conocimiento efectivo que el comprador haya tenido acerca de la falsedad de las declaraciones y garantías, antes de la firma del contrato o del cierre, puede ser esgrimido por el vendedor como una excusa o defensa válida frente a una demanda del comprador por infracción de declaraciones y garantías. Si bien tanto el comprador como el vendedor otorgan y reciben declaraciones y garantías, en la práctica la mayor parte de estas son dadas por el vendedor, y recibidas por el comprador. Por eso, en este artículo me referiré a las declaraciones y garantías del vendedor, en beneficio del comprador. Además, dado que a falta de estipulación de las partes, resulta aplicable el derecho de fondo que rige el contrato, me referiré primero a la forma en que se ha respondido a esta pregunta en otros países en que se ha discutido el tema, y luego explicaré cómo pienso que ella debiera ser contestada en Chile.

El comprador puede adquirir conocimiento de la falsedad de las declaraciones y garantías a partir de la información que le entregue el vendedor (por ejemplo, a través de una disclosure letter o de un anexo de revelaciones), de su propia investigación o por medio de terceros ${ }^{7}$. Que el comprador sepa que una o más declaraciones y garantías son falsas no implica necesariamente que el vendedor también posea tal conocimiento. Bajo una regla de responsabilidad estricta, no se requiere efectuar un juicio de valor sobre la conducta del declarante demandado; esto, es irrelevante si el declarante sabía o no que una declaración estaba incumplida y si comunicó o no al receptor que la declaración era falsa ${ }^{8}$.

3 Burman y Chighizola (2014) p. 214; Barros y Rojas (2010) p. 513.

4 Barros y Rojas (2010) p. 520.

5 Véase el concepto de closing en Garner (2009) p. 291, YrarrázaVal (2012) p. 156 y Stark (2007) p. 20.

6 Sobre el cierre de negocios, véase Zuloaga (2018).

Christou (2001) p. 347.

8 Barros (2006) pp. 446 y 475; y Barros y Rojas (2010) p. 520. 
Este artículo se divide en ocho secciones, incluida esta introducción. En la sección II, me referiré brevemente a la manera en que las declaraciones y garantías son entendidas y funcionan en Inglaterra y en Estados Unidos, dado que ellas tienen su origen en las representations and warranties del Common Law9. En la sección III explicaré que el efecto del conocimiento del comprador puede ser regulado por las partes en el contrato, mediante la incorporación de una cláusula sand-bagging o de una cláusula anti-sandbagging. En la sección IV, examinaré los principales argumentos que se han esgrimido en el Common Law sobre la relevancia o irrelevancia del conocimiento del comprador. En la sección V, revisaré el estado de la cuestión en la doctrina española. En la sección VI, me referiré a la doctrina nacional sobre la incorporación de declaraciones y garantías contractuales. En la sección VII, argumentaré que, en el Derecho chileno, a falta de regulación contractual, el conocimiento efectivo del comprador sobre la falta de veracidad de las declaraciones y garantías antes de la firma del contrato o del cierre, afecta su derecho a reclamar de la infracción y, por lo tanto, constituye una defensa que el vendedor puede esgrimir válidamente. En la sección VIII, expondré las conclusiones que se desprenden del análisis precedente.

\section{ORIGEN DE LA REPRESENTATION Y LA WARRANTY EN EL COMMON LAW}

El derecho inglés y el derecho estadounidense son muy similares en cuanto a la manera en que tratan la representation y la warranty, lo que permite referirse a ambos conjuntamente, sin perjuicio de destacar los aspectos en que difieren.

\section{Representation y MisRepresentation}

Representation es "la declaración de un hecho pasado o presente, efectuada en un momento para inducir a una parte a actuar" ${ }^{10}$. Si este hecho resulta ser falso, se estará ante una misrepresentation, esto es, "la comunicación de información falsa -ya sea a través de palabras (una declaración falsa) o a través de una conducta"; siendo el silencio generalmente insuficiente ${ }^{11}$. Esta declaración falsa induce al receptor a celebrar un contrato con el declarante $^{12}$. Por lo tanto, en principio ella es previa al contrato. Sin embargo, es común que las representations se incorporen al contrato.

Existen tres clases de misrepresentation: fraudulenta o dolosa; negligente; e inocente -esto es, con prescindencia de la conducta del declarante-, la que da lugar a responsabilidad estricta ${ }^{13}$.

La misrepresentation está sujeta a los siguientes requisitos:

\footnotetext{
Barros y Rojas (2010) p. 512.

10 Stark (2007) pp. 9 y 12.

11 Cartwright (2016) p. 177; y SMith (2006) p. 254.

12 Allen (1988) pp. 11 y 16.

13 Epstein (1999) p. 546.
} 
(i) Consiste en la declaración falsa sobre un hecho, presente o pasado, en consideración al momento en que se efectúa la declaración. Sin embargo, en algunos casos la misrepresentation puede consistir en una declaración sobre el derecho ${ }^{14}$.

(ii) La declaración debe ser relevante y -salvo aquella inocente- debe ser formulada de manera fraudulenta o negligente. Que la declaración sea relevante significa que debe ser apta para inducir a un destinatario razonable a celebrar un contrato ${ }^{15}$. Una declaración sobre hechos triviales, cuya falsedad puede causar poco o ningún daño a su receptor, es irrelevante ${ }^{16}$. Que la declaración sea fraudulenta implica que quien la emite es consciente de su falsedad e intenta engañar a la otra parte ${ }^{17}$.

(iii) La parte a quien se dirige la declaración debe haber creído o confiado en ella y haber sido inducida a consentir en la celebración del contrato ${ }^{18}$. La confianza opera como vínculo causal entre la misrepresentation y el daño sufrido por el receptor de la declaración $^{19}$. Por lo tanto, si el destinatario de una representation tenía conocimiento efectivo de que esta era falsa al momento en que fue formulada, no tiene derecho a reclamar, puesto que en tal caso no ha existido misrepresentation ${ }^{20}$. En efecto, el receptor que conocía de antemano la misrepresentation pudo haber desistido de contratar o contratado en otros términos. Si optó por perseverar en el contrato, es porque no permitió que la misrepresentation afectara su juicio ${ }^{21}$. Además, el hecho de que el receptor de la declaración supiera de antemano que esta era falsa, excluye el vínculo causal entre la representation y el daño: mal puede aquel alegar que dicha declaración lo indujo a celebrar el contrato.

Sin embargo, si el receptor tuvo la oportunidad de descubrir la misrepresentation pero no lo hizo, dispondrá de las acciones propias de la misrepresentation ${ }^{22}$.

(iv) En el derecho norteamericano se exige que la confianza que el receptor deposita en la declaración esté justificada. No lo estará si es evidente que la declaración es falsa o si ella no podía ser considerada seriamente ${ }^{23}$. Por su parte, en el derecho inglés, se requiere que la declaración sea inequívoca, esto es, debe ser entendida claramente y sin ambigüedades $^{24}$. Si la declaración puede ser comprendida en más de un sentido, el receptor deberá probar en qué sentido la entendió, y que en este particular sentido, ella resultó ser falsa ${ }^{25}$.

Ahora bien, la parte afectada por una misrepresentation puede hacer valer dos acciones. En primer lugar, cualquiera sea la clase de misrepresentation, el contratante afectado puede rescindir el contrato, con el efecto de que las partes serán restablecidas a la situación

14 Cartwright (2016) p. 177; y De La Maza (2010) pp. 191 y 192.

15 De La Maza (2010) p. 193.

16 Farnsworth (2004) p. 244; y EpSTEIN (1999) p. 563.

17 Farnsworth (2004) p. 243.

18 CARTWRight (2016) p. 178.

19 Franklin et al. (2011) p. 1251; Aguayo (2011) p. 72; y Cartwright (2016) p. 176.

20 Stark (2007) p. 13; Allen (1988) p. 16; Treitel (2007) p. 369; y De La Maza (2010) p. 194.

Allen (1988) p. 16.

2 Treitel (2007) p. 370; y Farnsworth (2004) p. 248.

3 Farnsworth (2004) p. 247.

4 De La Maza (2010) p. 190.

Allen (1988) p. 20. 
anterior a la celebración del contrato, debiendo procederse a las restituciones mutuas de lo que se hayan entregado y pagado recíprocamente ${ }^{26}$. La rescisión es la consecuencia de un defecto en la formación del contrato: la misrepresentation ${ }^{27}$. La rescisión del contrato puede producirse mediante la notificación extrajudicial que la parte afectada efectúa a la otra, o bien a través del inicio de un procedimiento judicial ${ }^{28}$. En segundo lugar, si la información incorrecta fue proporcionada negligente o fraudulentamente, la parte afectada tiene derecho a que se le indemnicen los perjuicios sufridos ${ }^{29}$.

\section{WARRANTY Y BREACH OF WARRANTY}

La warranty es una cláusula contractual en cuya virtud una parte garantiza a la otra la veracidad de ciertos hechos contenidos en una declaración y se obliga a indemnizar los daños que sufra el destinatario en caso que tales hechos sean falsos ${ }^{30}$.

Para que la parte afectada tenga derecho a indemnización, debe probar la infracción de la warranty y el daño que dicha infracción le produjo. No es necesario probar la negligencia de la parte que otorgó la warranty ${ }^{31}$, de suerte que su incumplimiento genera responsabilidad estricta ${ }^{32}$.

La confianza o reliance es un elemento que proviene del derecho de Torts y que, en cierta forma, puede tener injerencia en las warranties ${ }^{33}$. En Estados Unidos no existe consenso sobre si el receptor de la warranty debe haber confiado o creído en la veracidad de aquella. Así, en algunos estados, el receptor de una warranty tiene derecho a demandar la indemnización de los perjuicios, aunque al momento del cierre del contrato haya sabido que ella era falsa ${ }^{34}$.

La parte afectada por el incumplimiento de una warranty puede reclamar la indemnización de perjuicios con el fin de que sea puesta en la situación en que se encontraría de haber sido verdadera la afirmación. Luego, la warranty protege el interés de expectativa o expectation interest ${ }^{35}$.

\footnotetext{
${ }^{26}$ En general se emplean las expresiones rescission, avoidance y termination. Véase STARK (2007) pp. 14 a 16; Keeton et al. (1984) p. 730; Farnsworth (2004) pp. 246 y 254; Cartwright (2016) pp. 177 a 180; Allen (1988) pp. 29, 31 y 37; Smith (2006) pp. 254 y 259; Franklin et al. (2011) p. 1234; Perillo (2009) p. 293; Beale et al. (2010) p. 444; Treitel (2007) pp. 398 y 405.

27 Treitel (2007) p. 403.

28 Allen (1988) p. 30; y SMith (2006) p. 260.

29 Beale et al. (2010) p. 507; Farnsworth (2004) p. 243; Stark (2007) p. 14; Epstein (1999) p. 570; Treitel (2007) p. 390; y CARTWRight (2016) pp. 180 y 181. Sin embargo, en Inglaterra bajo la Misrepresentation Act de 1967 es posible que el juez conceda una indemnización de perjuicios aun tratándose de una misrepresentation en que no hay culpa ni dolo, y que no fue incorporada al contrato. Véase Treitel (2007) p. 398.

30 SMith (2006) p. 193; Christou (2001) p. 346; Corbin (1988) p. 21; y STARK (2007) pp. 9 y 13.

31 KeEton et al. (1984) p. 729.

32 Perillo (2009) p. 294; Macaulay et al. (2010) p. 562; y Atiyah (1990) p. 281.

33 MASSON (2009) p. 508.

34 WeST y SHAH (2007) p. 4.

35 Allen (1988) pp. 9 y 156; y Atryah (1990) p. 320. Sobre el interés de expectativa, véase Fuller y Perdue (1936) p. 54
} 
Por otra parte, la infracción de una warranty no otorga a la parte afectada el derecho a rescindir el contrato, remedio que -como señalé- sí está disponible en caso de una misrepresentation. De ahí que al receptor de una declaración convenga incorporar tanto representations como warranties $^{36}$.

Sin embargo, también hay que considerar que en la práctica contractual en Estados Unidos e Inglaterra, en general, los conceptos representations y warranties se usan indistintamente, relativizándose la distinción conceptual entre ambos términos a tal punto que se identifican ${ }^{37}$. En vista de ello, cabe preguntarse qué sucede con el elemento de confianza o reliance, propio de la misrepresentation. Esta cuestión, como se verá en la sección IV, ha sido respondida de forma diferente en los derechos estadounidense e inglés.

\section{REGULACIÓN EN EL CONTRATO DEL CONOCIMIENTO DEL COMPRADOR}

Las partes pueden regular en el contrato que celebren el efecto que tendrá el conocimiento por parte del comprador de la falsedad de las declaraciones y garantías, antes del cierre.

Por un lado, ellas pueden neutralizar los efectos del conocimiento por parte del receptor de las declaraciones y garantías mediante la incorporación de una cláusula prosandbagging -como se conoce en Estados Unidos-, en cuya virtud dicho conocimiento deviene irrelevante, esto es, no priva al destinatario de las acciones o remedios legales para reclamar del incumplimiento de las declaraciones y garantías. Un ejemplo de tal cláusula es el siguiente: "El derecho a indemnización, pago, reembolso u otro remedio basado en una declaración, garantía, covenant u obligación no será afectado por... cualquier investigación efectuada o por el conocimiento adquirido en cualquier momento, sea anterior o posterior a la firma de este contrato o a la fecha de cierre, respecto a la exactitud o inexactitud, o cumplimiento de dicha declaración, garantía, covenant u obligación"38.

Por otro lado, las partes pueden estipular una cláusula anti-sandbagging, mediante la cual el declarante se exime de responder por la infracción de las declaraciones y garantías en caso que el receptor conozca de la falsedad de las mismas antes del cierre ${ }^{39}$. Un ejemplo de tal cláusula es el siguiente: "Ninguna de las partes será responsable bajo esta cláusula por daños que resulten de o se relacionen con la inexactitud o el incumplimiento de cualquier declaración o garantía en este contrato, si la parte que solicita indemnización por tales daños tuvo conocimiento del incumplimiento antes del cierre" 40 .

Ahora bien, si las partes no regulan el efecto del conocimiento por el comprador de la falsedad de las declaraciones y garantías, el asunto deberá resolverse según el derecho de fondo aplicable al contrato, a lo que me referiré a continuación.

\footnotetext{
${ }^{6}$ STARK (2006).

7 West y Shah (2007) p. 5; y Adams (2008) p. 287.

8 Miziolek y Angelakos (2013) p. 30.

39 West y Shah (2007) p. 5; Miziolek y Angelakos (2013) p. 31; y Shadden (2014) p. 463.

${ }^{40}$ Miziolek y Angelakos (2013) p. 31.
} 


\section{DISCUSIÓN EN EL COMMON LAW SOBRE EL EFECTO DEL CONOCIMIENTO DEL COMPRADOR}

\section{ESTADOS UNIDOS: LAS DECLARACIONES Y GARANTÍAS SE COMPRAN}

En Estados Unidos es posible encontrar sentencias que se pronuncian sobre la discusión que es objeto de este artículo. Una de ellas es la sentencia dictada en el caso CBS Inc. v. Ziff-Davis Pub. Co. ${ }^{41}$. CBS y Ziff-Davis celebraron un contrato de compraventa por el cual la primera adquirió una empresa dueña de 12 revistas. En el contrato, Ziff-Davis declaró y garantizó a CBS que los estados financieros del target habían sido preparados conforme a los principios de contabilidad generalmente aceptados y que ellos reflejaban razonablemente la situación financiera del negocio. El contrato quedó sujeto a un cierre, e incluyó una cláusula según la cual todas las declaraciones y garantías debían ser verdaderas y correctas al tiempo del cierre, y sobrevivirían al cierre, no obstante cualquier investigación efectuada por CBS.

Antes del cierre, CBS hizo su propia investigación sobre la empresa, descubriendo información que le llevó a creer que los estados financieros no habían sido preparados conforme a los principios de contabilidad generalmente aceptados, ni reflejaban razonablemente la situación financiera de la empresa. Por ello, CBS escribió a Ziff-Davis que en su opinión las declaraciones sobre los estados financieros eran falsas o inexactas.

Ziff-Davis respondió a CBS diciendo que su carta no tenía mérito, reiterando la veracidad de lo declarado en el contrato y advirtiendo a CBS que se habían cumplido las condiciones para el cierre, de modo que si CBS no concurría al mismo, Ziff-Davis ejercería todos los derechos y remedios legales que le correspondían.

Las partes firmaron un documento en que reconocieron la existencia de una disputa entre ellas y acordaron seguir adelante con la compraventa de la empresa en el entendimiento mutuo que "el cierre no constituye una renuncia a ninguno de los derechos o defensas que cualquiera de las dos partes pueda tener" ${ }^{42}$. El mismo día, las partes suscribieron la compraventa.

Luego, CBS demandó a Ziff-Davis por incumplimiento de garantías contractuales, alegando haber pagado un precio excesivo en relación al que habría pagado si Ziff-Davis hubiese cumplido las declaraciones y garantías que efectuó. Ziff-Davis alegó que CBS nunca había creído en la veracidad de las declaraciones y garantías sobre estados financieros, en base a la investigación que esta llevó a cabo antes del cierre. CBS replicó haber "comprado" las declaraciones y garantías formuladas por Ziff-Davis; sostuvo que las garantías otorgadas por Ziff-Davis equivalían a una promesa de mantener a CBS indemne ante el evento que sus declaraciones resultaran ser falsas; y afirmó que -no obstante sus dudas- decidió perseverar en el negocio precisamente a causa del otorgamiento de las garantías por Ziff-Davis.

La Corte de Apelaciones de Nueva York acogió la demanda. Declaró que la cuestión a dilucidar no era si CBS creyó en la veracidad de la información garantizada, sino si creyó que estaba comprando la promesa de veracidad efectuada por Ziff-Davis. Enfatizó que las

${ }^{41}$ CBS Inc. v. Ziff-Davis Pub. Co., 75 N.Y.2d 496 (1990).

${ }^{42}$ CBS Inc. v. Ziff-Davis Pub. Co., 75 N.Y.2d 496 (1990) p. 501. 
garantías son parte del contrato. Habiéndose acreditado que CBS compró dicha promesa, la Corte condenó a Ziff-Davis a indemnizar los daños causados a CBS, no obstante las dudas de esta sobre la existencia de los hechos contenidos en la declaración ${ }^{43}$.

Llama la atención que, en algunas partes, la sentencia indica que CBS tuvo dudas sobre las garantías, mientras que en otras afirma que supo de la falsedad de las mismas. La duda sobre la veracidad de ciertas garantías y el conocimiento acerca de su falsedad debiesen ser tratadas de manera diferenciada. Es razonable que el receptor de las garantías que duda sobre la veracidad de estas, pueda reclamar de su infracción. De hecho, esta es una de las funciones de las garantías: relevar al destinatario de la carga de verificar si estas son correctas o no ${ }^{44}$. En cambio, no es razonable que el receptor de las garantías que sabe de antemano que estas son falsas, y por lo tanto se encuentran incumplidas, pueda reclamar con posterioridad de su incumplimiento. Dado que antes del cierre Ziff-Davis negó tajantemente que las garantías fuesen falsas, es posible sostener que CBS tenía dudas sobre estas.

Resulta interesante el voto disidente del juez Bellacosa. Sostuvo que el comprador no puede demandar a un vendedor por la infracción de una garantía en la que el primero eligió no confiar y, a pesar de ello, contrató. En efecto, CBS tenía derecho a desistirse del contrato antes del cierre si las declaraciones y garantías resultaban ser falsas. Sin embargo, prefirió confiar en su propia investigación y decidió seguir adelante con la compraventa. Luego, CBS renunció a su derecho a confiar en las declaraciones y garantías antes del cierre ${ }^{45}$.

Tal como se señaló, un argumento esgrimido en este caso para justificar que el comprador puede reclamar de la infracción de las declaraciones y garantías, aun si conocía su falsedad de antemano, es que el comprador compró las declaraciones y garantías, es decir, pagó por ellas ${ }^{46}$.

Esta afirmación merece un análisis. En efecto, si bien es razonable entender que las declaraciones y garantías son negociadas por las partes, tal como el precio de la empresa y las demás cláusulas del contrato, el comprador no puede creer que está comprando algo que sabe falso. Esta idea está presente en Galli v. Metz, que también se rige por la ley de Nueva York ${ }^{47}$. Este caso es relevante porque en él un tribunal federal -la Corte de Apelaciones del Segundo Circuito- reexamina el caso CBS v. Ziff-Davis, restringiendo su alcance.

Frank Galli y otros vendieron la empresa petrolera Betuna Corporation (incluyendo sus filiales Peterson y PSM) a James y Kathleen Metz. Posteriormente, los compradores fueron notificados por la Agencia de Protección Ambiental del hallazgo de residuos peligrosos que excedían los niveles permitidos en uno de los inmuebles de Peterson. Los compradores demandaron a los vendedores por la infracción de la siguiente garantía: "Ni Betuna ni los Vendedores conocen o tienen razón para estar al tanto de cualesquiera hechos que puedan resultar en... reclamos ...que puedan afectar negativamente el negocio o condición ...de Betuna o de sus propiedades" ${ }^{38}$.

${ }_{33}$ CBS Inc. v. Ziff-Davis Pub. Co., 75 N.Y.2d 496 (1990) pp. 503 y 504.

44 Barros y Rojas (2010) p. 514.

45 CBS Inc. v. Ziff-Davis Pub. Co., 75 N.Y.2d 496 (1990) p. 507.

46 Whitehead (2011) p. 1.085; y Perillo (2009) p. 294.

47 Galli v. Metz, 973 F.2d 145 (2d Cir. 1992).

48 Galli v. Metz, 973 F.2d 145 (2d Cir. 1992). 
El tribunal de primera instancia determinó que el problema de contaminación en el inmueble fue revelado por los vendedores a los compradores antes del cierre.

Los compradores alegaron que su conocimiento de la contaminación era irrelevante, ya que desde el caso CBS v. Ziff Davis, la confianza o reliance no es un elemento de la infracción de una garantía.

La Corte de Apelaciones del Segundo Circuito distinguió este caso de CBS v. ZiffDavis. En CBS v. Ziff-Davis existió una disputa entre las partes antes del cierre sobre la exactitud de ciertas garantías. El comprador cuestionó la veracidad de dichas garantías, pero el vendedor rechazó el cuestionamiento. Entonces las partes cerraron el contrato. En cambio, Galli y Metz estaban de acuerdo en que ciertas garantías no eran exactas al momento del cierre. La Corte sostuvo que "cuando un comprador cierra un contrato con conocimiento pleno y aceptación de los hechos revelados por el vendedor que constituirían una infracción de las garantías bajo el contrato, el derecho del comprador a reclamar posteriormente de dicha infracción se extingue", y agregó que "en esta situación, a menos que el comprador se reserve expresamente sus derechos bajo las garantías (como lo hizo CBS en Ziff-Davis), pensamos que el comprador ha renunciado a [reclamar de] la infracción”9.

La Corte consideró pertinente distinguir si los compradores conocieron el problema de la contaminación $-y$, por lo tanto, la falsedad de la garantía- a través de los vendedores o de un tercero. En el primer caso, los vendedores tienen un argumento sólido para afirmar que la garantía fue renunciada por los compradores. En el segundo caso, en cambio, cabe entender que los compradores adquirieron las garantías de los vendedores como un seguro frente a reclamos futuros. Este argumento fue reiterado por la misma Corte en Rogath v. Siebenmann, al establecer que "si el vendedor revela por adelantado la inexactitud de ciertas garantías, no puede decirse que el comprador -a falta de una reserva expresa de sus derechos- creyó que estaba comprando una promesa del vendedor sobre la veracidad de las garantías" 50 .

En consecuencia, siguiendo esta lógica, es claro que la cláusula pro-sandbagging también puede ser considerada como objeto de negociación y de compra por parte del comprador. El hecho de que un contrato no incluya dicha cláusula puede obedecer a que las partes no negociaron al respecto o a que si bien el comprador la solicitó, el vendedor no estuvo dispuesto a otorgarla. Luego, si las partes nada han dicho al respecto, no podría afirmarse que el comprador que compra las declaraciones y garantías, también está comprando una cláusula pro-sandbagging.

\section{INGLATERRA: EL CONOCIMIENTO DEL COMPRADOR ES RELEVANTE EN LA DECISIÓN DE} NEGOCIOS, INCLUYENDO LA DETERMINACIÓN DEL PRECIO DE LA COMPAÑÍA

Otro argumento que se ha desarrollado en el Common Law a favor de la idea de que el conocimiento del comprador sí perjudica sus derechos frente al vendedor, es el vínculo que existe entre el conocimiento del comprador y su decisión de negocios, según explico a continuación.

\footnotetext{
49 Galli v. Metz, 973 F.2d 145 (2d Cir. 1992).

50 Rogath v. Siebenmann, 129 F.3d 261 (2d Cir. 1997).
} 
El conocimiento de la empresa a adquirir es un antecedente que incide significativamente en la determinación del precio que el comprador está dispuesto a pagar por ella. Luego, no es razonable que el comprador se desentienda de ese conocimiento, reclamando por la infracción de declaraciones y garantías que sabía incumplidas, antes de la firma del contrato o del cierre.

En Inglaterra, este argumento ha sido analizado a propósito de los casos Eurocopy v. Teesdale e Infiniteland Ltd and Anor v Artisan Contracting Ltd and Anor. En primer lugar, en Eurocopy $v$. Teesdale, la actora compró al demandado la totalidad de las acciones de Teesdale \& Co. Ltd. Los vendedores otorgaron la siguiente warranty: "No hay hechos materiales o circunstancias en relación a los activos, pasivos, obligaciones, negocios o la condición financiera de la Compañía que no haya sido revelada completamente por escrito en la Disclosure Letter que, de ser dada a conocer, razonablemente podría haber influido afectando la decisión del comprador de celebrar este Contrato o la decisión de cualquier otro comprador de adquirir las Acciones" ${ }^{\text {"1 }}$.

Eurocopy demandó a los vendedores por la infracción de dicha warranty, sosteniendo que cierto hecho no fue incluido en la Disclosure Letter entregada por los vendedores. Estos se defendieron alegando que Eurocopy conocía el hecho en cuestión y que no obstante ello decidió celebrar el contrato. La High Court falló en contra del demandante, entre otras razones, porque este sabía de antemano que la Disclosure Letter era incompleta, de suerte que el alegar su infracción constituía una conducta deshonesta. El comprador recurrió en contra de dicha decisión ante la Court of Appeal, la que confirmó el fallo de alzada, pues el comprador celebró el contrato a sabiendas de los hechos reclamados. Estimó que el conocimiento de los hechos y circunstancias relevantes por parte del comprador debió incidir en la valoración de la compañía efectuada por este y, por tanto, fue determinante en el precio ofrecido por el mismo. Agregó que el hecho de que el comprador supiera que la Disclosure Letter era incompleta le impedía -sin incurrir en un acto deshonesto- confiar en las declaraciones y garantías. Si bien este juicio terminó por transacción, la sentencia citada ha tenido una influencia importante en la práctica contractual anglosajona ${ }^{52}$.

En segundo lugar, en Infiniteland Ltd and Anor v Artisan Contracting Ltd and Anor, la Court of Appeal reafirmó que los derechos y remedios del comprador ante la infracción de una warranty pueden o podrían ser afectados por el conocimiento adquirido por aquel mediante una investigación de la compañía, hecha por él mismo u otra persona a su nombre ${ }^{53}$.

Por lo tanto, dado que antes de la firma del contrato o del cierre, el comprador puede modificar o dejar sin efecto su decisión de negocios, el comprador que adopta una decisión de negocios u ofrece un precio en base a información que sabe falsa, pierde el derecho a reclamar la responsabilidad emanada del incumplimiento de las declaraciones y garantías.

A continuación me referiré a la manera en que ha sido tratado este tema por la doctrina española.

\footnotetext{
51 Eurocopy v Teesdale [1992] B.C.L.C 1067.

52 McNaughton et al. (2018) parágrafos 12 y 13; y Thompson (2014) parágrafo 1-08.

53 Infiniteland Ltd and Anor v Artisan Contracting Ltd and Anor [2005] EWCA Civ. 758.
} 


\section{ESPAÑA: RACIONALIDAD DEL COMPRADOR, BUENA FE Y TEORÍA DE LOS ACTOS PROPIOS}

La doctrina española ha sostenido que el conocimiento del comprador afecta su derecho a reclamar de las declaraciones y garantías, en base a las nociones de racionalidad, buena fe y actos propios que explicaré a continuación.

El comprador racional que se enfrenta a la falsedad de ciertas declaraciones y garantías antes de la firma del contrato o del cierre puede desistirse de contratar o perseverar en el contrato, ya sea acordando una reducción en el precio o la incorporación de una cláusula especial de indemnity o cobertura de riesgos ${ }^{54}$. En la práctica es frecuente que en los contratos de compraventa de empresas que contemplan firma y un cierre, se estipule como condición suspensiva que las declaraciones y garantías del vendedor sigan siendo ciertas al cierre. Si no lo son, el comprador puede desistirse del contrato, porque la condición ha fallado, o bien puede renunciar a la condición, si estima que la infracción es irrelevante, y seguir adelante con la compraventa.

Como indica Ángel Carrasco, "no actúa racionalmente un comprador que conoce la existencia de una contingencia relevante para él y sin embargo no repercute esta situación en el precio, contentándose, por el contrario, con la existencia de una simple e inútil repetición por parte del vendedor de que tal contingencia no existe" ${ }^{55}$. Agrega que el comprador que conoce una contingencia puede superar el problema incorporando en el contrato una cobertura de riesgos o specific indemnity ${ }^{56}$. La specific indemnity tiene como supuesto un acuerdo de las partes, en tanto la responsabilidad por infracción de declaraciones y garantías emana de un incumplimiento ${ }^{57}$.

La specific indemnity es una figura anglosajona en que el conocimiento del comprador sobre la falsedad de los hechos contenidos en la declaración es irrelevante ${ }^{58}$. Luego, al incorporar una specific indemnity, la pregunta clave no es si la cosa objeto del contrato vale menos, sino si tuvo lugar el evento que la gatilla y cuánto debe pagarse ${ }^{59}$.

Ahora bien, si el vendedor no está dispuesto a convenir un ajuste del precio, o a otorgar una specific indemnity, el comprador que desee perseverar con la transacción al menos debe asegurarse que el contrato incluya una reserva expresa de su derecho a reclamar por la infracción de las declaraciones y garantías ${ }^{60}$. En Estados Unidos, eso es lo que hizo CBS en CBS Inc. v. Ziff-Davis Pub. Co.

Por otra parte, la doctrina española también sostiene que la buena fe y la teoría de los actos propios impiden al receptor de declaraciones y garantías que sabe falsas, alegar

\footnotetext{
54 Aguayo (2011) p. 195; West y Shah (2007) p. 6; Ruutel y Saunders (2005) p. 4; Young y Kitching (1995) p. 338; Quaintance (2002) p. 18; y Shadden (2014) pp. 468 y 469.

55 Carrasco (2013) p. 333.

56 Carrasco (2013) p. 334. En la misma línea, Gómez (2007) p. 37.

57 Aguayo (2011) pp. 209, 212 y 213.

58 Thompson (2014) parágrafo 1-08; y McNaughton et al. (2018) parágrafo 6.

59 Young y Kitching (1995) p. 338.

${ }^{60}$ Quaintance (2002) p. 18.
} 
luego su incumplimiento ${ }^{61}$. En efecto, el receptor de una declaración que, habiendo tomado conocimiento de una información devaluadora antes de contratar, posteriormente reclama de ella "como si no supiera nada", sin dudas contradice su conducta anterior, lo que permite al emisor de la declaración defenderse esgrimiendo la doctrina de los actos propios en contra del primero ${ }^{62}$.

\section{RECEPCIÓN EN CHILE DE LAS DECLARACIONES Y GARANTÍAS CONTRACTUALES}

En Chile tampoco se distingue entre declaraciones y garantías ${ }^{63}$. En efecto, se usan indistintamente las expresiones "declaraciones y garantías", "manifestaciones y garantías" o "representaciones y garantías". Las declaraciones y garantías consisten en una estipulación de las partes en cuya virtud incorporan al contrato un régimen de responsabilidad por la falta de veracidad de cierta información que un contratante, generalmente el vendedor, proporciona al otro, a menudo el comprador.

Los remedios disponibles en Chile frente a la infracción de declaraciones y garantías son la indemnización de perjuicios y el ajuste del precio. A ellos se agrega, en algunos casos, la resolución del contrato ${ }^{64}$.

En el Common Law, la parte que otorga e incumple las representations and warranties incurre -como es la regla en sede contractual- en responsabilidad estricta. En cambio, la responsabilidad contractual en Chile se funda tradicionalmente en la culpa, con base en el artículo 1547 del Código Civil ("CC") ${ }^{65}$, no obstante que para parte importante de la doctrina contemporánea las obligaciones de resultado -cuyo sería el caso de las declaraciones y garantías $^{66}$ - dan lugar a una responsabilidad estricta ${ }^{67}$.

Cabe preguntarse entonces si el incumplimiento de las declaraciones y garantías en un contrato sujeto a ley chilena desencadena responsabilidad estricta o por culpa, y, por ende, qué excusas puede esgrimir el emisor de las mismas cuando estas resultan ser falsas.

Según Enrique Alcalde, la responsabilidad por infracción de declaraciones y garantías requiere del dolo o culpa del emisor. Luego, el declarante puede eximirse de responsabilidad probando que empleó la diligencia debida al efectuar declaraciones que resultaron ser falsas. Sin embargo, reconoce que el declarante generalmente debe observar la máxima diligencia, dado que se encuentra en mejor posición para aseverar o refutar la veracidad de lo que afirma y, por tanto, para garantizar dicha circunstancia al receptor ${ }^{68}$. Pero esta responsabilidad por culpa levísima se aproxima bastante a una responsabilidad estricta.

61 Aguayo (2011) pp. 196 y 197, nota al pie 451; y PAYet (2009) p. 85

62 Aguayo (2011) p. 196, nota al pie 451.

63 Barros y Rojas (2010) p. 515; e Yrarrázaval (2012) pp. 478 y 479.

64 Barros y Rojas (2010) p. 522.

65 Alessandri (2010) p. 38; Claro Solar (2013) Tomo XI, p. 440; y Gatica (1959) p. 75.

66 Barros y Rojas (2010) p. 518.

67 Pizarro (2008) p. 263; Peñailillo (2009) p. 229; y Barros (2009) pp. 311 a 313.

68 Alcalde (2008) pp. 250-252; y Alcalde (2018) pp. 358-361. 
Por su parte, Ricardo Quezada sostiene que la indemnización de perjuicios por infracción a las declaraciones y garantías requiere de la culpa del vendedor que las otorga, aunque este responde de culpa leve que se aprecia de forma calificada, a semejanza de lo que ocurre con el mandatario que ha sido remunerado. Con todo, el emisor de declaraciones y garantías falsas podría invocar en su defensa el caso fortuito y la inexigibilidad de otra conducta ${ }^{69}$.

A su vez, para Barros y Rojas no es necesario juzgar la conducta de quien efectúa la declaración: la sola disconformidad entre lo declarado y la realidad da lugar a un incumplimiento contractual. Luego, la infracción de declaraciones y garantías genera una responsabilidad estricta y no admite excusa alguna, ni siquiera el caso fortuito ${ }^{70}$.

En cuanto al conocimiento del receptor de las declaraciones y garantías sobre su falsedad, Barros, conociendo en calidad de árbitro de derecho de la venta de una cadena de farmacias cuyas partes no regularon las consecuencias del mismo, consideró que “...en principio, el conocimiento que pueda haber tenido XX [comprador demandante] en virtud del due diligence sobre las materias declaradas y garantizadas por $\mathrm{ZZ}$ [vendedor demandado] no afecta la responsabilidad de esta por la eventual falsedad o inexactitud de las mismas"71.

Barros y Rojas citan el caso CBS Inc. v. Ziff-Davis Pub. Co, que si bien es un precedente importante en el estado de Nueva York y en los demás estados que han adoptado una posición pro-sandbagging, ha sido criticado en los estados que tienen un punto de vista anti-sandbagging, entre los cuales destaca California. Como se vio más arriba, el punto no es pacífico, ni en Estados Unidos ni en Inglaterra ${ }^{72}$.

En la misma línea, Cárdenas y Reveco descartan que la diligencia del declarante y el caso fortuito puedan ser admisibles como excusas frente al incumplimiento de declaraciones y garantías ${ }^{73}$.

Por mi parte, considero razonable entender que las declaraciones y garantías se rigen en Chile, al igual que en el Common Law, bajo una regla de responsabilidad estricta: en principio, basta la disconformidad entre lo declarado y la realidad, y que dicha disconformidad cause daño al receptor, para que tenga lugar la obligación indemnizatoria del declarante. Sin embargo, considero que el receptor de las declaraciones y garantías, que, antes de la firma del contrato o del cierre, toma conocimiento sobre la falsedad de aquellas, y no se hace cargo de ello a través de la renegociación del contrato, de la incorporación de una specific indemnity o al menos de una reserva de derechos, incurre en negligencia. La negligencia consiste en desentenderse de ese conocimiento, en no hacer algo para evitar el daño, cuando todavía se está a tiempo para ello. Esa pasividad es imprudente. De esta forma, el receptor de las declaraciones, a semejanza de la víctima de un accidente, participa en la causación de su propio daño ${ }^{74}$. Dicha negligencia puede ser opuesta como una excusa váli-

\footnotetext{
69 Quezada (2015) pp. 38-41.

70 Barros y Rojas (2010) pp. 514, 519 y 526.

${ }^{71}$ Fallo CAM Santiago Rol 1526-2012 dictado el 10 de julio de 2015, considerando $8^{\circ}$.

72 Respecto a la discusión en Estados Unidos, véase DUCHEmin (1999) pp. 689 y siguientes; WhiteHEAD (2011) p. 1083; y SHADDEN (2014) pp. 470 y 471.

73 Cárdenas y Reveco (2018) p. 156.

74 Sobre la culpa de la víctima, véase Bahamondes y Pizarro (2012); Cooter y Ulen (2008) p. 478. A favor de la aplicabilidad del artículo 2330 del Código Civil en responsabilidad contractual, véase SAN MARTín (2015).
} 
da por el demandado, tal como puede hacerlo el victimario, para excluir su responsabilidad estricta o al menos para reducir la indemnización reclamada.

\section{HIPÓTESIS: EN CHILE, EL CONOCIMIENTO EFECTIVO DEL COMPRADOR ACERCA DE LA FALSEDAD DE LAS DECLARACIONES Y GARANTÍAS, ANTES DE LA FIRMA O DEL CIERRE DEL CONTRATO, AFECTA SU DERECHO A RECLAMAR DE DICHA INFRACCIÓN}

\section{Planteamiento}

En nuestro Derecho parece razonable entender que el receptor de las declaraciones y garantías no requiere probar que confió en la veracidad de estas. Pero también resulta razonable admitir que el emisor de las mismas pueda eximirse de responsabilidad, o al menos reducirla, probando, conforme lo dispuesto en el artículo 1698 del CC, que el destinatario conocía efectivamente su falsedad, antes de la firma del contrato o del cierre.

El estándar de prueba de dicho conocimiento debiese ser exigente, por eso empleo el adjetivo "efectivo". Desde luego, y como señalé a propósito del caso CBS Inc. v. Ziff-Davis Pub. Co, las dudas que tenga el comprador sobre la veracidad de las declaraciones y garantías no son suficientes para impedirle reclamar de ellas. Entre la duda, por una parte, y el conocimiento efectivo, por la otra, debiese trazarse una línea divisoria clara.

Los argumentos de derecho comparado descritos más arriba me parecen aplicables en Chile para sustentar mi hipótesis, incluyendo el razonamiento a partir de la buena fe y la doctrina de los actos propios. Esta ha sido aplicada frecuentemente por la Corte Suprema, entre otras, en materia de contratos ${ }^{75}$.

En la misma línea, en un fallo arbitral dictado en Chile por Alejandro Romero como árbitro mixto, se estableció que el conocimiento previo que tuvo el demandante reconvencional de un incumplimiento de su contraparte, le impide invocar esa circunstancia para reclamar posteriormente del incumplimiento ${ }^{76}$. El árbitro sostuvo que "pretender desconocer en este juicio los efectos de esa información llevaría a infringir una de las manifestaciones del principio de la buena fe contractual, reconocido en el artículo 1546 del CC, que sanciona como inadmisible toda pretensión lícita pero objetivamente contradictoria con respecto al propio comportamiento anterior efectuado por el mismo sujeto"77.

A continuación desarrollaré argumentos adicionales que sustentan mi hipótesis.

2. El CONOCIMIENTO DEL COMPRAdOr SObRE CIRCUNSTANCIAS DEVALUADORAS DE LA COSA LE PRIVA DE ACCIONES FRENTE AL VENDEDOR

La técnica de declaraciones y garantías contractuales es extraña al Código de Bello. Sin embargo, en la regulación de la compraventa, se observa que el conocimiento que tenga el comprador, al momento de celebrar la compraventa, sobre circunstancias que de alguna

75 Corral (2011) y Contardo (2010).

76 Considerando $10^{\circ}$ del fallo CAM Santiago Rol 711-2007 dictado por Alejandro Romero Seguel.

77 Considerando $10^{\circ}$ del fallo CAM Santiago Rol 711-2007 dictado por Alejandro Romero Seguel. 
forma devalúan la cosa, lo priva de ciertas acciones frente al vendedor, que tendría de no mediar dicho conocimiento.

Así, por ejemplo, al tratar la venta de cosas que no existen, el artículo 1814 del CC establece: "El que vendió a sabiendas lo que en el todo o en una parte considerable no existía, resarcirá los perjuicios al comprador de buena fe". Ahora bien, si el vendedor y el comprador sabían al tiempo del contrato que la cosa vendida no existía, o solo el comprador lo sabía, el vendedor no debe indemnización alguna: en ambos casos, el perjuicio que ha podido sufrir el comprador es fruto de su acción voluntaria, es decir, le es imputable ${ }^{78}$.

Asimismo, si el comprador conoció las evicciones al tiempo de celebrar el contrato y, no obstante ello, lo celebra, se entiende que renuncia tácitamente al saneamiento ${ }^{79}$.

Análogamente, el vicio oculto o redhibitorio es aquel que el comprador desconoce al tiempo del contrato. En cambio, si el defecto de la cosa es conocido por aquel, o este debía conocerlo en razón de su profesión u oficio, o no pudo ignorarlo sin negligencia grave de su parte (no empleó un mínimo de diligencia para cerciorarse de que la cosa está exenta de vicios $^{80}$ ), no habrá vicio redhibitorio y el comprador no tendrá acción redhibitoria ni de rebaja del precio ${ }^{81}$. Es decir, si el vicio no es oculto, "se presume que el comprador, al adquirir la cosa, no atribuyó al vicio ninguna importancia y la aceptó con él”82.

Excepcionalmente, a propósito de la lesión enorme, es irrelevante el conocimiento que tengan o no el vendedor y el comprador al tiempo de la compraventa ${ }^{83}$. Por lo tanto, la parte perjudicada por la lesión enorme -vendedor o comprador- puede reclamar de ella incluso si estaba de mala fe al contratar, es decir, si sabía que el precio convenido daba lugar a la lesión enorme. Sin embargo, en rigor la lesión enorme no es una circunstancia devaluadora de la cosa, sino una desproporción entre la cosa y su precio, que el legislador considera intolerable, prohibiendo expresamente la renuncia de la acción para impetrarla ${ }^{84}$.

Además de la compraventa, es interesante la regulación del contrato de arrendamiento. El arrendatario se encuentra en una posición parecida a la del comprador: al celebrar el contrato, suele tener menos información sobre la cosa que el arrendador. El efecto del conocimiento que tenga el arrendatario, al momento de contratar, sobre circunstancias devaluadoras de la cosa, es similar al efecto recién descrito respecto del conocimiento del comprador: le priva de una serie de acciones, que tendría de no mediar dicho conocimiento. Por ejemplo, el arrendatario no tiene acción de saneamiento en caso de evicción de la cosa ajena, si sabía que esta era ajena ${ }^{85}$. Tampoco habrá lugar a la acción de indemnización de perjuicios, si el arrendatario conocía la imposibilidad de entregar que afecta al arrendador ${ }^{86}$; si las reparaciones que requiere la cosa procedían de causa conocida por el arrendatario al

\footnotetext{
78 Alessandri (2003) Tomo I, volumen 1, pp. 195 y 196.

79 Alessandri (2003) Tomo II, volumen 1, pp. 151 y 153

80 LÓPEZ (2017) p. 442.

81 Artículo 1858 CC

82 Alessandri (2003) Tomo II, volumen 1, p. 202.

83 Alessandri (2003) Tomo II, volumen 2, p. 764.

84 Artículo 1892 CC.

${ }^{85}$ Artículo 1916, inciso 20 CC.

${ }^{86}$ Artículo 1925 , inciso $2^{\circ} \mathrm{CC}$.
} 
tiempo del contrato ${ }^{87}$; si el arrendatario contrató a sabiendas del vicio que afecta a la $\operatorname{cosa}^{88}$; si el arrendatario sabía que el arrendador no era dueño absoluto de la $\operatorname{cosa}^{89}$; y si el arrendatario conocía el mal estado del edificio ${ }^{90}$. Finalmente, el artífice no tendrá acción para reclamar el precio o salario, si conocía el vicio de la materia suministrada por el que encargó la obra y la cosa perece ${ }^{91}$.

También es relevante la regulación que efectúa el CC sobre el error y el dolo. En ambos casos, el conocimiento que tenga el comprador, al tiempo de contratar, sobre la falsedad de una declaración, impedirá que se configure un caso de error o de dolo.

Respecto al error, mal podría alegar el comprador haber sido víctima de una falsa representación de la realidad, si conocía la circunstancia devaluadora de la cosa al momento de la compraventa: "el error indica que no se tiene conocimiento verdadero y cabal de una cosa o hecho; que se ignora algo a su respecto"; y es error "creer verdadero lo que es falso, o falso lo que es verdadero" 92 . Por lo tanto, saber que es falso lo que es falso, no puede constituir error.

En cuanto al dolo, cabe preguntarse si la declaración conscientemente falsa de una de las partes puede llevar a la anulación de un contrato ${ }^{93}$. En este caso, la conducta del declarante es particularmente reprochable. Sin embargo, si la falsedad de esa declaración es conocida por su receptor, este mal podría alegar que fue inducido a celebrar el contrato; pues " $[\mathrm{s}] \mathrm{i}$ la persona a quien se quiere engañar, descubre el fraude y no deja por eso de contratar, no hay ya dolo y el contrato es perfectamente válido"94.

Asimismo, en materia de derecho de seguros, la divergencia entre la información que el asegurado entrega al asegurador y el riesgo real o verdadero, guarda cierta similitud con las declaraciones y garantías que una parte otorga a la otra, y su falta de veracidad. En derecho de seguros, el asegurador evalúa y determina el riesgo que asume en base a la declaración de riesgos que efectúa el asegurado ${ }^{95}$. Si la información que el asegurado entrega al asegurador es inexacta o errónea, y se produce el siniestro, el asegurador queda exonerado de su obligación de indemnizar al asegurado, o bien tiene derecho a una rebaja en la indemnización ${ }^{96}$. Sin embargo, "[e]stas sanciones no se aplicarán si el asegurador, antes de celebrar el contrato, ha conocido los errores, reticencias o inexactitudes de la declaración o hubiere debido conocerlos; o si después de su celebración, se allana a que se subsanen o los acepta expresa o tácitamente" ${ }^{17}$. Es decir, si al celebrar el contrato el asegurador conocía el riesgo o sabía que la declaración hecha por el asegurado era falsa, aquel deberá indemnizar a este ${ }^{98}$.

\footnotetext{
87 Artículo 1928, inciso $4^{\circ} \mathrm{CC}$.

88 Artículo 1934 CC.

89 Artículo 1959 CC.

90 Artículo 1975 CC.

91 Artículo $2000 \mathrm{~N}^{\circ} 3 \mathrm{CC}$.

92 Claro Solar (2013) Tomo XI, pp. 128 y 127, respectivamente.

93 De la Maza (2016).

94 Claro Solar (2013) Tomo XI, p. 199.

95 Ríos (2014) p. 54.

96 Artículo 525 inciso $4^{\circ}$ del Código de Comercio.

${ }^{7}$ Artículo 525 inciso final del Código de Comercio.

98 Ríos (2014) p. 76.
} 
La diferencia entre el seguro y las declaraciones y garantías es que en el primero, el asegurado declara y el asegurador indemniza si se produce el siniestro, en tanto que en las segundas, la misma parte efectúa las declaraciones y garantías e indemniza al otro contratante, si aquellas no son veraces. A pesar de esta diferencia, el seguro resulta interesante porque en él también se plantea el problema de la falta de veracidad de la información suministrada por una parte a la otra, y el conocimiento por parte del receptor de la información, al momento de contratar, de la falta de veracidad de aquella. El asegurador no puede desentenderse de su conocimiento para dejar de indemnizar al asegurado, pues en base a dicho conocimiento evaluó el riesgo. Por su parte, tampoco es razonable que el receptor de declaraciones y garantías se desentienda de su conocimiento para reclamar una indemnización, porque basándose en dicho conocimiento, el receptor de declaraciones y garantías adoptó una decisión de negocios y ofreció un precio al vendedor, según se explicó al analizar el derecho inglés.

\section{DiLIGENCIA DEL COMPRADOR Y CONFIANZA RAZONABLE}

Si bien no tengo conocimiento de sentencias dictadas en Chile en que se haya presentado la discusión objeto de este artículo, sí hay, en cambio, sentencias en que se ha analizado la situación del receptor de declaraciones cuya falsedad ignoraba ${ }^{99}$. En algunas de ellas, se ha fallado que por tratarse de declaraciones cuya falsedad el receptor pudo haber conocido, de haberlas verificado desplegando un mínimo de diligencia, su reclamo no puede ser acogi$\mathrm{do}^{100}$. A ello se agrega que si para un contratante es importante la afirmación que recibe del otro, debe cerciorarse con mediana diligencia de la efectividad de lo afirmado ${ }^{101}$.

Esta línea argumental ha sido criticada por Iñigo de la Maza, quien señala que el receptor de una declaración tiene la expectativa de que se le entregue correctamente información, es decir, puede confiar razonablemente en la veracidad de la declaración, y no es negligente al no comprobar su veracidad ${ }^{102}$. Este razonamiento me parece acertado. En el mismo sentido, Barros y Rojas señalan que "el receptor de una garantía no tiene que creer que la afirmación es verdadera: el propósito de la garantía es precisamente relevar a ese contratante de la carga de verificar la verdad de la información”, siendo innecesario juzgar si el receptor de la declaración confió o podía confiar en ella ${ }^{103}$.

Sin embargo, Barros y Rojas agregan que "las declaraciones son en la práctica elementos de la negociación, porque el contrato es convenido precisamente en sus términos porque la parte que recibe la declaración puede confiar en su verdad"104. Ahora bien, el receptor podrá confiar en la verdad de la declaración si ignora que esta es falsa. Sostener que el receptor de una declaración que sabe falsa, aún puede confiar en ella, parece un contrasentido. En definitiva, el receptor de declaraciones y garantías puede confiar en ellas, siempre que desconozca que son falsas, y no debe probar que confía en ellas. Pero si el receptor

99 Véase De La Maza (2017) y De La Maza (2016).

100 Véase Empresa Minera Oriel Gerardo y Cía. Ltda. con Comercial Minera San Cristóbal Ltda. (2014).

101 Véase Valdebenito SaAvedra con Fuentes Rojas (2016).

102 De La Maza (2017) p. 682.

103 Barros y Rojas (2010) p. 514.

104 Barros y Rojas (2010) p. 526. 
sabe que dichas declaraciones son falsas (lo que debe acreditar el otorgante de las mismas), no puede confiar en ellas ni, por tanto, reclamar de su incumplimiento.

Adicionalmente, conforme a las normas que regulan el pago, el acreedor -comprador- no puede ser obligado a recibir otra cosa que lo que se le debe ${ }^{105}$. Luego, el comprador que conoce de la falsedad de una declaración puede rehusarse a recibir la cosa y no está obligado a firmar el contrato o a concurrir al cierre.

\section{El COMPRADOR QUE CONOCE EFECTIVAMENTE LA FALSEDAD DE LAS DECLARACIONES Y GARANTÍAS HA CONTRARRESTADO LA ASIMETRÍA DE INFORMACIÓN \\ Una de las funciones de las declaraciones y garantías es "encauzar la información re-} levante para el negocio jurídico que se pretende hacer, incorporándola al contrato" ${ }^{106}$. Esta función se aprecia particularmente en la compraventa, en la que suele existir una asimetría informativa entre el vendedor y el comprador ${ }^{107}$ : aquel tiene mayor conocimiento sobre la cosa, y le cuesta menos obtenerlo, que a este. Pero si el comprador ha adquirido conocimiento de la falsedad de las declaraciones y garantías, en cierta medida ha neutralizado dicho desequilibrio.

Por lo tanto, en el caso en que el comprador conoce efectivamente de antemano que las declaraciones y garantías son falsas, antes del cierre o de la firma del contrato, se frustra una de las funciones de las declaraciones y garantías, cual es la de disminuir la asimetría de información entre las partes. En otras palabras, las garantías del comprador valen menos ${ }^{108}$.

\section{Ausencia De Riesgo}

Las declaraciones y garantías constituyen un mecanismo mediante el cual las partes distribuyen los riesgos de un contrato. Cabe preguntarse, entonces, cuál es el riesgo sobre el que se contrata en las declaraciones y garantías.

En primer lugar, Barros, en su calidad de árbitro en el caso de la venta de una cadena de farmacias, señaló que, "[l] as declaraciones y garantías tienen por objeto atribuir el riesgo de falsedad o inexactitud a la parte que ha revelado la información...” ${ }^{109}$. Según Barros y Rojas, "salvo que el contrato admita una interpretación inequívocamente diversa, la función de la declaración que una parte hace a la otra como parte del acuerdo contractual es atribuir el riesgo de su falta de veracidad a la parte que la formula"110. Desde el punto de vista del receptor de las declaraciones y garantías, podría haber riesgo de falta de veracidad solo en tanto este no sepa efectivamente que las declaraciones y garantías son falsas. La veracidad de las declaraciones y garantías se analiza en relación a un marco de tiempo definido. Es por eso que frente a su infracción, no es posible pedir el cumplimiento forzado ${ }^{111}$.

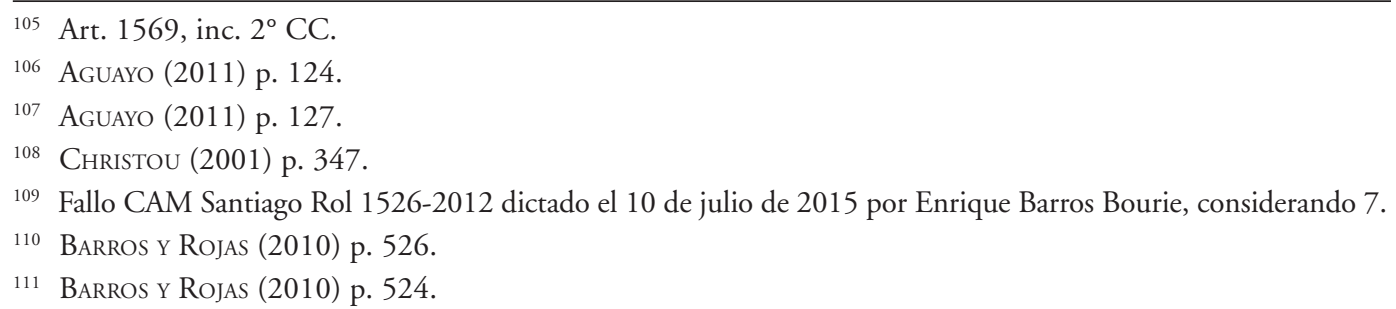


Sin embargo, si el receptor de las declaraciones y garantías sabe de antemano que estas son falsas, entonces no hay riesgo de que no sean veraces: efectivamente no son veraces.

En segundo lugar, también se ha señalado que el riesgo sobre el cual recaen las declaraciones y garantías es el riesgo de lo desconocido ${ }^{112}$. Bajo esta perspectiva, las declaraciones y garantías permiten al comprador protegerse de pasivos ocultos o desconocidos por él, existentes al tiempo de la venta. Pero si el pasivo es conocido por el comprador, es evidente que él no podría confiar en declaraciones y garantías que niegan la existencia de dicha deuda.

En tercer lugar, las declaraciones y garantías comprenden el riesgo de que en el futuro tengan lugar contingencias que afecten la empresa o cosa adquirida. En este caso el riesgo es que una declaración y garantía que se sabe falsa -y por lo tanto incumplida-, produzca o no un perjuicio cuantificable en el futuro. Barros y Rojas señalan que "las cláusulas de garantías de pasivo u otras, que corresponden en general a las declaraciones y garantías, tienen por preciso objeto que el vendedor o los antiguos controladores de la empresa transferida asuman responsabilidad por un incremento de los pasivos que no pudo considerarse al tiempo de concretarse la venta"113. Sin embargo, en el caso en que el comprador conoce de la falsedad de una declaración, en cambio, tiene la posibilidad de considerar, antes de la firma del contrato o del cierre, el incremento de los pasivos, por lo que mal podría alegar que se trata de pasivos inesperados. Para esta situación, como ya se señaló, lo que el receptor de una declaración y garantía puede solicitar al vendedor, es una cobertura de riesgos o specific indemnity ${ }^{114}$.

En fin, de admitirse que el conocimiento efectivo de la falsedad de las declaraciones y garantías por parte del receptor de ellas, constituye una excepción o defensa válida frente a una demanda indemnizatoria, dicho conocimiento debe ser acreditado por la parte que las otorgó: el vendedor. De esta manera el vendedor se eximirá de su obligación de indemnizar bajo los términos del artículo 1698 del CC, o al menos podrá alegar su reducción.

\section{CONCLUSIONES}

1. Si las partes de un contrato no han regulado el efecto que puede tener el conocimiento efectivo del comprador acerca de la falsedad de las declaraciones y garantías antes de la firma del contrato, o del cierre, concurren varias razones para sostener que el derecho del comprador a reclamar de la infracción se ve afectado por dicho conocimiento.

2. El comprador, al formular una oferta por la cosa o empresa a adquirir, tiene en cuenta la información sobre esta. Tal como se ha destacado en el Common Law, esta información es relevante para la adopción de la decisión de negocios, incluyendo la determinación del precio. La decisión de negocios aún puede ser modificada o dejada sin efecto antes de la firma del contrato o del cierre, si la cosa o empresa no reúne las características que son relevantes para el comprador. Por lo tanto, mal podría el comprador alegar que ha adoptado una decisión de negocios en base a información que sabe falsa.

\footnotetext{
112 Masson (2009) p. 519; y Young y Kitching (1995) p. 339.

113 Barros y Rojas (2010) p. 523.

114 West y SHAh (2007) p. 6.
} 
3. Como afirma la doctrina española, un comprador racional que sabe que una o más declaraciones y garantías son falsas, puede desistirse del contrato o intentar renegociarlo, mediante la reducción del precio o la incorporación de una cláusula de specific indemnity. Si el comprador no logra acordar un ajuste en el precio o una specific indemnity, y desea seguir adelante con el contrato, al menos debiera reservarse expresamente su derecho a reclamar. Además, el comprador que reclama de una infracción de las declaraciones y garantías que conocía antes de la firma o del cierre, actúa contradictoriamente y, por tanto, vulnera la buena fe.

4. En el Derecho chileno, para que el conocimiento previo del comprador sobre la falta de veracidad de las declaraciones y garantías afecte su derecho a reclamar de ellas, dicho conocimiento debe ser "efectivo". Las dudas que pueda tener el comprador sobre la veracidad de las declaraciones y garantías no deberían perjudicar su derecho a reclamar.

5. Si bien el uso de declaraciones y garantías contractuales es extraño al CC, en la regulación que este efectúa de la compraventa, se observa que el conocimiento del comprador, al momento de celebrar la compraventa, sobre circunstancias que de alguna forma devalúan la cosa, lo priva de ciertas acciones frente al vendedor, que tendría de no mediar dicho conocimiento. Esta lógica también se observa en la regulación de los contratos de arrendamiento y de seguro.

6. La idea de la confianza razonable permite sostener que el receptor de una declaración que sabe falsa no puede reclamar de ella. La confianza razonable presupone que el receptor de una declaración ignore que esta es falsa. Si el receptor de la declaración sabe que ella es falsa, mal podría confiar razonablemente en ella.

7. Las declaraciones y garantías permiten que el vendedor revele información al comprador sobre la cosa o empresa que este desea adquirir, disminuyendo de esta forma la asimetría informativa que suele existir entre ambas partes. El comprador que ha tomado conocimiento efectivo de ciertos aspectos de la empresa o cosa comprada que contradicen las declaraciones, ha contrarrestado dicha asimetría.

8. La cláusula de declaraciones y garantías es una forma de distribuir el riesgo entre las partes de un contrato. Si se considera como riesgo la posibilidad de que las declaraciones y garantías sean falsas, y el comprador sabe que efectivamente son falsas, no hay riesgo, pues no existe la posibilidad de que sean falsas o no: lisa y llanamente lo son. Luego, si se estima que el riesgo recae sobre lo desconocido -pasivos ocultos-, tratándose de un pasivo que es conocido por el comprador, mal podría confiar en declaraciones y garantías que niegan su existencia. Finalmente, si se analiza el riesgo de que en el futuro se materialicen contingencias que afecten la cosa o empresa adquirida, es razonable que el receptor de declaraciones y garantías solicite al vendedor una specific indemnity, en que el conocimiento del comprador sobre dicha contingencia resulta irrelevante.

9. En el Derecho chileno, frente a la infracción de declaraciones y garantías contractuales, debiese considerarse como una defensa válida por parte de quien las otorgó, el hecho de que el receptor de ellas haya conocido efectivamente su falsedad antes de la firma o del cierre del contrato. Incumbe al otorgante de las declaraciones acreditar dicho hecho, ya que ello le permitirá eximirse de responsabilidad, o al menos atenuarla. 


\section{BIBLIOGRAFÍA CITADA}

Adams, Kenneth A. (2008): A Manual of Style for Contract Drafting (Estados Unidos, American Bar Association, 2a edición).

Aguayo, Juan (2011): Las manifestaciones y garantías en el Derecho de contratos español (Pamplona, Thomson Reuters, primera edición).

AlCAlde, Enrique (2008): "La cláusula de 'declaraciones y garantías' en la venta de una empresa: naturaleza jurídica y efectos”, Revista Actualidad Jurídica, No 17: pp. 243-255.

Alcalde, Enrique (2018): La Responsabilidad Contractual (Santiago, Ediciones Universidad Católica de Chile).

Alessandri Rodríguez, Arturo (2003): De la Compraventa y de la Promesa de Venta (Santiago, Editorial Jurídica de Chile).

Alessandri Rodríguez, Arturo (2010): De la Responsabilidad Extracontractual en el Derecho Civil chileno (Santiago, Editorial Jurídica de Chile).

Allen, David K. (1988): Misrepresentation (Londres, Sweet \& Maxwell).

AтіYaH, P. S. (1990): Essays on Contract (Oxford, Oxford University Press, primera edición).

Bahamondes, Claudia y Pizarro, Carlos (2012): "La exposición de la víctima al daño: desde la culpabilidad a la causalidad", Revista de Derecho de la Pontificia Universidad Católica de Valparaíso, vol. 39, No 2: pp. 39-52.

Barros, Enrique (2006): Tratado de Responsabilidad Extracontractual (Santiago, Editorial Jurídica de Chile).

Barros, Enrique (2009): "El contrato y el hecho que causa daño como antecedentes de la Responsabilidad”, en Pizarro, Carlos (edit.), Estudios de Derecho Civil IV (Santiago, Legal Publishing Chile) pp. 297-313.

Barros, Enrique y Rojas, Nicolás (2010): "Responsabilidad por declaraciones y garantías contractuales", en Comisión Organizadora VII Jornadas Nacionales de Derecho Civil (edit.), Estudios de Derecho Civil V (Santiago, Legal Publishing Chile) pp. 511-526.

Beale, Hugh; Fauvarque-Cosson, Bénédicte; Rutgers, Jacobien; Tallon, Denis, y Vogenauer, Stefan (2010): Cases, Materials and Texts on Contract Law (Portland, Hart Publishing, segunda edición).

Burman, Guillermo, y Chighizola, Diego (2014): "Contratos de compraventa de acciones: el desafío de generar valor a partir de una adecuada estructuración contractual”, Revista Jurídica de la Universidad de San Andrés, No 1: pp. 194-224.

Cárdenas, Hugo, y Reveco, Ricardo (2018): Remedios Contractuales (Santiago, Thomson Reuters).

Carrasco, Ángel (2013): “Manifestaciones y garantías y responsabilidad por incumplimiento”, en Carrasco, Ángel y Álvarez, José María (edits.), Adquisiciones de Empresas (Pamplona, Editorial Aranzadi S. A., cuarta edición).

Cartwright, John (2016): Contract Law (Oxford y Portland, Hart Publishing, tercera edición).

Christou, Richard (2001): Drafting Commercial Agreements (Londres, Sweet \& Maxwell, segunda edición). 
ReCART ApFelbeCK, Joaquín — "Sobre el conocimiento del comprador, antes de la firma del contrato o del cierre ..."

Claro Solar, Luis (2013): Explicaciones de Derecho Civil chileno y comparado (Santiago, Editorial Jurídica de Chile).

Contardo, Juan Ignacio (2010): "La doctrina de los actos propios en la jurisprudencia civil chilena", Cuadernos de Extensión Jurídica de la Universidad de los Andes, $\mathrm{N}^{\circ} 18$ : pp. 81-102.

Cooter, Robert y Ulen, Thomas (2008): Derecho y Economía (México, D.F., Fondo de Cultura Económica, segunda edición).

Corbin, Arthur L. (1988): Corbin on Contracts (Saint Paul, West Publishing Co., primera edición).

Corral, Hernán (2011): "Aceptación jurisprudencial de la doctrina de los actos propios". Disponible en: https://www.elmercurio.com/Legal/Noticias/Analisis-Juridico/2011/10/06/Aceptacion-jurisprudencial-de-la-doctrina-de-los-actos-propios.aspx\#. Fecha de consulta: 20 de mayo de 2020.

De La Maza, Iñigo (2010): Los límites del deber precontractual de información (Pamplona, Editorial Aranzadi).

De La MaZa, Iñigo (2016): "Afirmaciones conscientemente falsas y mediana diligencia. A propósito de la sentencia de la Corte Suprema de fecha 4 de abril de 2016", Revista de Derecho Universidad Católica del Norte, $\mathrm{N}^{\circ}$ 2: pp. 311-326.

De La MAZA, Iñigo (2017): "El riesgo de la ignorancia: declaraciones deliberadamente falsas", en Comisión Organizadora XIV Jornadas Nacionales de Derecho Civil (edit.), Estudios de Derecho Civil XII (Santiago, Thomson Reuters) pp. 671-685.

Duchemin, Matthew J. (1999): "Whether Reliance on the Warranty is required in a Common Law Action for Breach of an Express Warranty", Marquette Law Review, vol. 82, No 3: pp. 689-711.

EPSTEIn, Richard (1999): Torts (Nueva York, Aspen Publishers).

Farnsworth, E. Allan (2004): Contracts (Nueva York, Aspen Publishers, cuarta edición).

Franklin, Marc A., Rabin, Robert L., y Green, Michael D. (2011): Tort Law and Alternatives (Nueva York, Foundation Press, novena edición).

Fuller, L.L. y Perdue, Jr, William R. (1936-1937): “The Reliance Interest in Contract Damages", The Yale Law Journal, vol. 46, No 1: pp. 52-96 y No 3: pp. 373-420.

Garner, Brian A. (edit.) (2009): Black's Law Dictionary (Saint Paul, West, novena edición).

Gatica, Sergio (1959): Aspectos de la indemnización de perjuicios por incumplimiento del contrato (Santiago, Editorial Jurídica de Chile).

GómEz, Fernando (2007): "El incumplimiento contractual en Derecho Español”. Disponible en: http://www.indret.com/pdf/466_es.pdf. Fecha de consulta: 8 de noviembre de 2018.

Keeton, W. Page; Dobbs, Dan B.; Keeton, Robert E.; y Owen, David G. (1984): Prosser and Keeton on the Law of Torts (Saint Paul, West Publishing Co., quinta edición).

López, Patricia (2017): "La naturaleza jurídica de la acción redhibitoria en el Código Civil chileno: ¿nulidad relativa, resolución por incumplimiento o rescisión propiamente tal?” Revista Chilena de Derecho, vol. 44 No 2: pp. 423-459.

Macaulay, Stewart; Braucher, Jean; Kidwell, John; y Whitford, William (2010): Contracts: Law in Action, Volumen 1 (New Providence, LexisNexis, tercera edición). 
Masson, Kabir (2009): "Paradox of presumptions: seller warranties and reliance waivers in commercial contracts", Vanderbilt Law Review, No 109: pp. 503-537.

McNaughton, Ross; Poxon, Matthew; y Dempster, Alexandria (2018): “Acquisitions: Representations Warranties and Disclosure". Disponible en: www.westlaw.co.uk. Fecha de consulta: 3 de julio de 2017.

MizioleK, Aleksandra y Angelakos, Dimitrios (2013): "Contract Drafting: Sandbagging: From poker to the world of mergers and acquisitions", Michigan Bar Journal, vol. 92: pp. 30-34.

PAYET, José Antonio (2009): "Reflexiones sobre el contrato de compraventa de empresas y la responsabilidad del vendedor", Revista Ius et Veritas, N 39: pp. 66-100.

Peñailillo, Daniel (2009): Obligaciones (Santiago, Editorial Jurídica de Chile).

Perillo, Joseph M. (2009): Callamari and Perillo on Contracts (Saint Paul, West, sexta edición).

Pizarro, Carlos (2008): "La culpa como elemento constitutivo del incumplimiento en las obligaciones de medio o de diligencia", Revista de Derecho de la Pontificia Universidad Católica de Valparaíso, vol. 31, No 2: pp. 255-265.

Quaintance, Jr., Robert F. (2002): “Can you sandbag? When a buyer knows that one of the seller's representations or warranties is untrue". Disponible en: https://www.debevoise.com/ /media/files/insights/publications/2002/02/the\%20private\%20equity\%20 report/files/view\%20report/fileattachment/winter\%202002.pdf. Fecha de consulta: 30 de agosto de 2018.

QuezaDA, Ricardo (2015): "La responsabilidad del vendedor por infracción a las declaraciones y garantías: resolución parcial, rebaja del precio e indemnización de perjuicios", Revista de Derecho, Escuela de Postgrado, No 8: pp. 17-46.

Ríos, Roberto (2014): El deber precontractual de declaración del riesgo en el seguro de daños (Santiago, Legal Publishing Chile).

Ruutel, Nicola y Saunders, Kathryn (2005): "Full and fair disclosure after Infiniteland". Disponible en: https://www.westlaw.co.uk. Fecha de consulta: 5 de julio de 2018.

San Martín, Lilian (2015): "Deberes de protección y culpa de la víctima: exposición imprudente al daño en responsabilidad contractual" Disponible en: https://www.elmercurio.com $/$ legal $/$ movil $/$ detalle aspx?Id=904294\&Path=/0D/CC/. Fecha de consulta: 10 de junio de 2020 .

SHAdDen, Stacey A. (2014): "How to sandbag your opponent in the unsuspecting world of high stakes acquisitions", Creighton Law Review, vol. 47: pp. 459-475.

Smith, Stephen A. J. (2006): Atiyah's Introduction to the Law of Contracts (Nueva York, Oxford University Press Inc., sexta edición).

Stark, Tina L. (2006): "Nonbinding Opinion. Another view on reps and warranties". Disponible en: https://www.americanbar.org/content/dam/aba/publications/blt/2006/01/ opinions-reps-warranties-200601.pdf. Fecha de consulta: 4 de enero de 2018.

Stark, Tina L. (2007): Drafting Contracts, How and Why Lawyers Do What They Do (Nueva York, Aspen Publishers, primera edición).

Thompson, Robert (2014): "Sinclair on Warranties and Indemnities on Share and Asset Sales”. Disponible en: https://www.westlaw.co.uk. Fecha de consulta: 4 de junio de 2018 . 
ReCART Apfelbeck, Joaquín — "Sobre el conocimiento del comprador, antes de la firma del contrato o del cierre ..."

Treitel, G.H. (2007): The law of contract (Londres, Thomson Reuters, decimo segunda edición).

West, Glenn D. y SHAH, Kim M. (2007): "Debunking the myth of the sandbagging buyer: when sellers ask buyers to agree to antisandbagging clauses, who is sandbagging whom?”, The M\&A Lawyer, vol. 11, No 1: pp. 3-7.

Whitehead, Charles K. (2011): "Sandbagging: Default rules and acquisition agreements", Delaware Journal of Corporate Law, vol. 36: pp. 1.081-1.115.

Young, John y Kitching, John (1995): "Buying and selling a business: warranties and indemnities", International Company and Commercial Law Review, Vol. 10, No 6: pp. 336-339.

Yrarrázaval, Arturo (2012): Diccionario Jurídico-Económico (Santiago, Ediciones Universidad Católica de Chile).

ZuloagA, Isabel (2018): "Algunas consideraciones acerca del cierre de negocios", en BAhamondes, Claudia y otros (edit.), Estudios de Derecho Civil XIII (Santiago, Thomson Reuters) pp. 371-400).

\section{JURISPRUDENCIA CITADA}

Chilena

empresa Minera Oriel Gerardo y Cía. Ltda. con Comercial Minera San Cristóbal Ltdda. (2014): Corte Suprema, 9 de septiembre de 2014 (acción de resolución de contrato con indemnización de perjuicios).

VAldebenito SAavedRa con Fuentes Rojas (2016): Corte Suprema, 4 de abril de 2016 (acción de resolución de nulidad de contrato por dolo).

Fallo CAM Santiago Rol 711-2007 dictado el 19 de mayo de 2007 por Alejandro Romero Seguel.

Fallo CAM Santiago Rol 1526-2012 dictado el 10 de julio de 2015 por Enrique Barros Bourie.

\section{ESTADOUNIDENSE}

CBS Inc. v. Ziff-Davis Pub. Co., 75 N.Y.2d 496 (1990).

Galli v. Metz, 973 F.2d 145 (2d Cir. 1992).

Rogath v. Siebenmann, 129 F.3d 261 (2d Cir. 1997).

INGLESA

Eurocopy v Teesdale [1992] B.C.L.C 1067.

Infiniteland Ltd and Anor v Artisan Contracting Ltd and Anor [2005] EWCA Civ. 758.

\section{NORMAS CITADAS}

Código Civil

Código de Comercio 